\title{
Thx 4 the msg: Assessing the Impact of Texting on Student Engagement and Persistence
}

\author{
Megan M. Tippetts ${ }^{1}\left(\mathbb{D} \cdot\right.$ Bobbi Davis $^{2} \cdot$ Stephanie Nalbone $^{3} \cdot$ Cathleen D. Zick $^{4}$
}

Received: 5 November 2020 / Accepted: 25 January 2022 / Published online: 16 February 2022

(c) The Author(s), under exclusive licence to Springer Nature B.V. 2022

\begin{abstract}
As colleges and universities strive to increase persistence and aid students in reaching graduation, they are utilizing alternative communication strategies like text messaging. Behavioral economics researchers suggest personalized, regular nudges can help college students make decisions that positively impact their college career and keep them on track for graduation. The current study presents the results of a randomized field experiment where a text messaging program was implemented in a large college at a public university. The intervention utilized a mixture of automated and personalized text messages from academic advisors and allowed for two-way communication between individual students and their major advisor. Mulitvariate analyses revealed the intervention had no impact on university persistence, but it did increase the odds of persisting in the college to the end of the semester, moving the average, overall college persistence rate from 93 to $95 \%$. Effects were concentrated on underclass students, whose persistence rate moved from 87 to $93 \%$ at the college level. Underclass students also showed statistically significant university persistence effects, moving from 90 to $95 \%$. Students who received texts but never engaged with the texting program were significantly less likely to request an advising appointment or to apply to be a student ambassador than were students in the control group. More research is needed to understand what motivates a student to engage with the texting software and to identify what the longer-term consequences of using text messaging to communicate with students might be.
\end{abstract}

Keywords Text messaging $\cdot$ Persistence $\cdot$ Behavioral economics $\cdot$ Behavioral nudges . Academic advising $\cdot$ Student success

Megan M. Tippetts

meg.tippetts@utah.edu

1 Department of Sociology, University of Utah, Salt Lake City, UT, USA

2 Department of Educational Leadership and Policy, CSBS Student Success Center, University of Utah, Salt Lake City, UT, USA

3 University of Utah Office of Institutional Analysis, University of Utah, Salt Lake City, UT, USA

4 Department of Family and Consumer Studies, University of Utah, Salt Lake City, UT, USA 


\section{Introduction}

It is widely recognized navigating college life can be challenging, especially for young adults living on their own for the first time. They must make choices regarding how much study time to schedule, whether to seek the assistance of an instructor when struggling with an assignment, and which of an array of classes to take. Students essentially face a choiceridden, educational world they must navigate while simultaneously attending to a multitude of competing activities. For students who are relatively young, these complex choices also arise at a developmental time when self-regulation abilities are not fully developed and when many will prioritize opportunities that favor immediate rather than delayed gratification (e.g., social media, online videos, going out with friends rather than studying for an exam) (Hanushek et al., 2016; Panek, 2014). Ultimately, the many incremental decisions students make may put them on trajectory that culminates in a bigger decision-whether to persist in their college studies.

Theory suggests one key to persistence and student success is the student's ability to navigate their new environment and integrate themselves into campus and academic life (Tinto 2015, 2017). Institutional attempts to reduce the complexity of academic life have taken many forms. Colleges and universities have invested in (1) optimizing the first-year experience (e.g., requiring freshmen to live on-campus, offering small, specialized firstyear courses), (2) promoting deeply engaged learning experiences (e.g., internships, undergraduate research, community engaged learning), (3) expanding campus life activities (e.g., recreation centers, clubs), and (4) growing academic supports (e.g., student wellness centers, student success advocates). For many colleges and universities, however, their biggest investment has been in hiring professionally, credentialed advising staff to replace faculty members who have historically been responsible for academic advising (Venit, 2017).

College connectedness, as seen through the lens of social identity theory and student involvement theory, is an essential part of the work of academic advisors as they are the primary conduit for information and advice on navigating academic life and graduating with a degree in a timely fashion (Jorgenson et al., 2018). Typically, advisors have met with individual students in their offices or over the phone. But, as students' time commitments have grown more numerous and as navigating college requirements has grown more complex, it has become challenging for advisors to communicate effectively with students. Busy students request phone or virtual appointments or send their questions to advisors via email. Student time constraints coupled with high advisor-to-advisee ratios means students may struggle to find open appointments to address time sensitive matters (Tuttle, 2000). In addition, information that is proactively communicated from advisors or departments to students via email often goes unread (Straumsheim, 2016; Langlois \& Klein, 2019).

Students are increasingly using their cell phones to navigate a variety of communication delivery modes (e.g., webpages, email, blogs). In this context, texting has been identified as a communication mode that has the potential to deliver key information from advisors in a manner that is more likely to be read by students. Behavioral economics theory suggests nudging can influence behavior by altering how choices are presented in a given environment (Ly et al., 2013; Thaler \& Sunstein, 2009). Additionally, when nudges come from a trusted source, decision-makers are more likely to consider the impact of the decision and the intention of the source (Krijnen et al., 2017). Thus, nudging via brief text messages from academic advisors to their advisees is hypothesized to have the potential to reduce informational complexity and promote student success by altering the environment in which students are presented with choices (Castleman, 2015). 
While a number of randomized field experiment (RFE) texting interventions have been undertaken with targeted populations (e.g., entering freshmen who have been identified as being at high risk for non-persistence), little is known about the effectiveness of such interventions in the general student population. In this study, we evaluate a RFE intervention involving semi-automated text messages sent from academic advisors to students over the course of one semester. We assess the impact of the RFE on both student engagement and persistence.

\section{Literature Review}

In recent years, researchers have begun applying the principles of behavioral economics to nudge college students toward options that enhance their probability of graduation. There is established evidence socio-demographic and economic factors are related to a student's persistence probability (Allen et al., 2008; Corbett et al., 2008; Davidson et al., 2009; Hagedorn et al., 2001; Hawley \& Harris, 2005; Wang, 2009). However, more recent research also identifies non-socioeconomic factors, such as, self-efficacy and a sense of belonging, as significant persistence indicators (Fishbane \& Fletcher, 2016; Page et al., 2020; Stewart et al., 2015; Stiles \& Wilcox, 2016; Tinto, 2015; Yeager et al., 2019). Self-efficacy relates to a student's ability to navigate college life, while a sense of belonging relates to a student's sense of connectedness to the college and campus faculty and staff (Stiles \& Wilcox, 2016; Tinto, 2015). In addition, college-age students often have not developed the cognitive skills to consider the long-term impact of their short-term decisions, particularly when met with numerous, complex options. Students face a multitude of decisions that could impact their academic careers (Casey et al., 2011; Castleman, 2015; Hanushek et al., 2016; Goldrick-Rab, 2010; Tough, 2019), from hanging out with friends and spending time online to studying, applying for financial aid, choosing course schedules from semester to semester, and in some cases riskier options, such as consuming drugs and/or alcohol. The challenge for colleges and universities has been pinpointing how to best address these nonacademic or socio-economic barriers to persistence.

Similarly, college and university institutional factors can have an impact on student persistence and retention. Marsh (2014) finds first-year retention rates were impacted by both student characteristics and institutional factors, such as institutional financial characteristics and faculty involvement. Tinto (2017) argues another institutional factor impacting student persistence is the perceived value of what they are learning.

Building on behavioral economics insights, colleges and universities have been exploring different strategies for reducing informational complexity with the goal of facilitating students' active decision making and promoting students' sense of belonging at the university (Boath et al., 2016; Boyd et al., 2020; Castleman, 2015; Castleman \& Page, 2014; Fishbane \& Fletcher, 2016, 2019; Tinto, 2015, 2017; Witten et al., 2017). Tinto (2015) reports students are often overburdened with information and struggle to find the motivation to continue their education. He argues early intervention with students through academic advising can set students on a path to graduation. Indeed, empirical studies reveal an impactful way to increase persistence is to connect students with academic advisors (Astin, 1975; Bai \& Pan, 2009; Bettinger \& Baker, 2014; DeilAmen \& Rosenbaum, 2003; Kot, 2014, Tippetts, et al., 2020). For example, Betting and Baker (2014) report students who met with an advising coach were 5\% more likely to persist compared to students in a control group. Additionally, Castleman and Meyer 
(2020) conclude the frequency of meeting with an academic advisor aids in the transition to college and increases student persistence, as well as a student's overall GPA.

Thaler and Sunstein (2009) argue decision making can be influenced by the way a choice is presented in a particular environment to the decision maker. Commonly referred to as choice architecture, researchers and policymakers are using nudging to present choices to decision-makers in ways that encourage them to make optimal selections (Ly et al., 2013). Thaler and Sunstein (2009) define a nudge as “... any aspect of the choice architecture that alters people's behavior in a predictable way without forbidding any options or significantly changing their economic consequences" (p. 6). Additionally, nudges must be "easy and cheap to avoid" (Thaler and Sunstein, 2009, p. 6). In other words, the nudge itself cannot have a clear financial incentive or restrict freedom of choice (Ly et al., 2013).

Krijnen and et al., (2017) have built upon the principles of choice architecture by adding the perceived intention of the choice architect, or nudger, is influential to the decisionmaker. They argue decision-makers are engaging social sensemaking, by considering the intentions and beliefs of the choice architect and how their decision may be construed by others (Krijnen et al., 2017). This suggests in the case of nudging students, recommendations from academic advisors would typically be viewed positively by students because advisors are viewed as promoting what is in the best interest of students.

Engagement with an academic advisor through texting is often an overlooked aspect of text messaging interventions, with few studies mentioning the impact of interacting with an advisor via text. Arnold et al. (2020) asked students who participated in advising via text about their experience. Using focus groups and text message queries, they reported that, overall, students enjoyed text messaging, noting it kept them on track toward success in their academic careers. However, little attention has been paid to the advisor's experience. Tippetts, et al. (2021) finds advisors were initially hesitant to add another form of communication to their already growing caseloads, but they eventually became supportive of the program after seeing its impact on students. Additionally, text messaging may aid advisors in time management by reducing the need for one-on-one appointments, as advisor-to-advisee ratios continue to rise (Tippetts, et al., 2021; Tuttle, 2000). Castleman and Page $(2015,2017)$ discovered the most significant impact of a text messaging campaign to reduce summer melt in newly graduated high school students was seen when they and/or their parents engaged with the counselor by responding to one or more texts throughout the summer. Indeed, research indicates engagement with the university and academic advising is important for semester-to-semester persistence (Kuh et al., 2008; Castleman, 2015; Kahn, 2014; Hanushek et al., 2016; Allen et al., 2008; Schwebel et al., 2008; Aljohani, 2016).

Numerous college administrators are implementing text messaging programs to nudge students to make decisions that support student success specifically by helping students access academic advisors, coaches, or mentors. Text messaging is appealing because past studies show them to be effective in changing students' behavior (Castleman \& Page, 2014, 2016a; Page \& Gehlbach, 2017; Selingo, 2018). For example, Castleman and Page (2014) use text messaging to connect newly graduated high school seniors and their parents with an advisor outside of their chosen university with the goal of reducing the "summer melt" of admitted freshman. Students who participated in the program were $7.1 \%$ more likely to enroll in college than those who did not participate. As another example, Page and Gehlbach (2017) use a chatbot to text newly admitted students at Georgia State University, where students who received messages through the chatbot were $3.3 \%$ points more likely to enroll on time than those in the control group. 
Yet, other researchers focus on using text messaging to promote student engagement and/or improve their time management, with mixed results. Oreopoulos et al. (2019) report no significant impact on academic outcomes when using text messaging and an online planning tool to remind struggling students of the benefits of improving time management skills and study habits. In contrast, Stone (2004) discovered text messaging to support new freshman positively impacted their time management strategies by providing a structured support system.

Only a few studies assess the impact of text messaging interventions on student persistence. One RFE uses text messaging nudges to remind students at a community college to refile their FAFSA. The authors conclude students who participated were $14 \%$ more likely to be continuously enrolled through the spring of their sophomore year (Castleman \& Page, 2016b). Castleman and Meyer (2020) used text messaging to reduce informational complexity for low-income students in 4-year colleges. They report students who participated in the text program were 1.7 to 2 times more likely to enroll the following semester than students who did not participate in the program. Mabel et al. (2019), find students late in their academic careers who were assigned to a personalized text message program saw fall to spring dropout decrease from 17.5 to $15 \%$. Similarly, Page, et al. (2020) used a chatbot to text students at varying academic levels across three aspects of academic life, (1) academic supports, (2) social and career supports, and (3) administrative processes. They report texts focused on administrative processes were the most effective at changing student behavior, with rates of filling out FAFSA and registering for the following fall semester approximately $3 \%$ points higher for students in the treatment group compared to those in the control group (Page et al., 2020). However, another study concludes text messages related to goal setting for new freshman did not impact second year persistence, GPA, or course credits (Dobronyi et al., 2017).

Differences in the conclusions of persistence studies may exist for several reasons. First, some of the persistence studies target specific student populations (e.g., entering freshmen). Second, studies vary in the length of time they follow students. Third, studies vary as to whether students are automatically enrolled in the texting program or if they must opt into the program, and this latter approach can create self-selection effects. Finally, personalized and proactive text messages that utilize choice architecture are likely to vary across studies.

Our study builds on existing research by using the principles of behavioral economics to tailor messages to a general student population and their interests (e.g., inviting students to attend major-specific events, promoting registration for a new course offering). We connect students with on-campus academic advisors who are experts on the requirements of the students' declared major, rather than using programs outside the university or upper-level student mentors. As a large college within a public university, we offered two definitions of persistence in our analyses, that of the university and that of the college. This distinction furthers the literature on what it means to persist for students and the colleges that support them. We add to the available literature by including students in all levels of the academic career, and examining how texting relates to persistence by career stage; investigating intermediate actions (e.g., students' initiation of advising appointments), discussing the impact of student engagement with the texting program; and automatically opting students into the program based on their major and having a texting capable phone number. 


\section{Methodology}

\section{The Setting}

The university has a $67 \%$ acceptance rate and a 6-year graduation rate of $70 \%$, which is $10 \%$ higher than the national average for public universities (National Center for Education Statistics, 2019). Approximately $67 \%$ of the undergraduates are White nonHispanic, while nationally, approximately $55 \%$ of undergraduates at public 4-year institutions are White non-Hispanic (Snyder et al., 2019). Forty-seven percent of the undergraduates at the university are female, which is in contrast to national figures where $57 \%$ of college students are female (Snyder et al., 2019). The college's composition differs somewhat in that $59 \%$ of the college's majors are female and $63 \%$ are White nonHispanic, suggesting that its demographic composition is closer to the national average than is the university as a whole. The university's overall persistence rate for first-time freshmen was $89 \%$ in 2017 , which parallels the national persistence rate for first-time students entering a 4-year college on a full-time basis (National Center for Education Statistics, 2019).

The college where the study was conducted is a "discovery" rather than a "destination" college for entering freshmen as most students do not declare a major in the college during their first year. Rather, they typically "discover" the majors in the college at a later point in time. In addition, approximately $40 \%$ of the majors are transfer students who have started their college education at either a 2-year school or another in-state, 2-year school.

In recent years, most of the college's communication with students has been conducted via email from the college's centralized academic advising center. The academic advising center has 14 full-time academic advisors who help students navigate the college's 11 different majors. Email messaging to undergraduate majors is typically focused on registration reminders, application deadlines for scholarships and graduation, and special events (e.g., college-sponsored public lectures). More recently, messages have also been distributed via a weekly student digest, on major-specific webpages, and on the college's website. Freshmen and sophomore declared majors have a mandatory academic advising appointment they are required to attend during the fall semester before they can register for spring semester classes. There are no mandatory spring semester advising appointments, nor are there any advising requirements for juniors, seniors and transfer students.

Single semester persistence is high with $95 \%$ of students re-enrolling at the university each semester and about $91 \%$ of students continuing within their declared major in the college each semester. However, when viewed over the course of the fall, spring, and summer semesters, the institution experiences considerable student churning as evidenced by the university's 6-year graduation rate of $62 \%$, which is similar to the national 6-year graduation rate of 62.4\% (National Center for Education Statistics, 2020; The Office of Budget and Institutional Analysis, 2020). Within the college, such student churning has budgetary implications as the college's student-focused budget is a function of a weighted rolling, 2-year average of number of majors, number of students who graduate, and student credit hours generated. The college administration thus adopted a texting program in the hopes it might promote student persistence and increase 6-year graduation rates within the college. 


\section{The Intervention}

During the 2019-2020 academic year, the $\underline{\text { Academic }}$ Success and Completion Enhancement (ASCENT) RFE was implemented in the college. The text messaging intervention used insights from behavioral economics to develop a text messaging plan designed to: (1) reduce informational complexity associated with the university, (2) build a sense of community within the college, and (3) nudge students to embrace optimal choices.

The intervention made use of a FERPA-compliant texting platform that is specifically designed for use in higher education. The platform allowed for two-way texting between students and academic advisors and secure integration of student data. It also had a blended messaging feature that enabled both automated responses for frequently asked questions, and personalized responses from advisors when automation was not $98 \%$ confident an automated response was appropriate. This feature was appealing as it reduced advisor time spent crafting individual responses. Those student replies requiring a personal response were addressed by advisors within at least two business days of receipt and students were informed there might be a lag in advisors' responses. ${ }^{1}$

During the fall semester, a small pilot texting intervention was undertaken with approximately 300 randomly selected students majoring in the college. Selected students were informed via text the college was piloting a text messaging program and subsequent messages would be sent from their major advisor. The goals of this pilot work were to assess if the intervention was reaching its targeted audience, to ascertain if the monitoring procedures (e.g., data collection, data management) were working properly, and to assess the level of staff support needed. Quantitative data on student engagement with the texting platform and opt-out rates were collected along with qualitative data gathered from focus groups undertaken with (1) participating students, and (2) the academic advisors.

We also sought advice from a noted expert on academically focused text messaging during the fall semester. The consultant provided guidance on the structure and style of our text messages. In addition, the consultant provided examples of infographics that had resonated with students in prior work. This information, in combination with advisor and student feedback, helped us prepare the ASCENT RFE for spring semester, where students were randomized into two treatment groups and a control group.

We hypothesized spring semester text messaging intervention would raise students' likelihood of engaging with the college and their likelihood of becoming active decisionmakers who would take ownership for their academic careers. Most importantly, we posited these text messages would also be associated with a higher likelihood of successfully persisting to the end of the semester. Two different measures of persistence were constructed. The first measure reflected the university's definition of persistence in that students were classified as persisting spring semester if they did not (1) formally withdraw, (2) take a formal leave of absence, or (3) drop all of their classes before the end of the term. The second measure reflected the perspective of the college in defining persistence. This measure added a fourth criteria to the university's definition of persistence by requiring that persisting students did not change from majoring in the college to majoring in another college during the semester in question. ${ }^{2}$

\footnotetext{
1 The text messaging platform provided local phone numbers that were used for a set number of students in each major. Students could save the phone number and use it to contact their advisor. Advisors used a web based platform to respond to students' texts.

2 Continuing to have an active major in the college is important from the college's perspective as its budget is, in part, a function of the number of undergraduates who have declared a major in the college.
} 
Examples of college engagement text messages included encouraging students to (1) apply for the college's student ambassador program, (2) proactively make an academic advising appointment, and (3) submit a college and/or a departmental scholarship application. Texts encouraging students to engage in active decision-making while reducing information complexity included messages focused on completing the FAFSA, how to access a degree audit report, highlighting the benefits of attending school summer semester, and registering for the next semester early. Following best practices in texting college students (Castleman, 2015; Castleman \& Page, 2014), these text messages were sent approximately once a week during the spring semester to those participants in the two treatment groups. Text messages were personalized by addressing students by their preferred name, and in the first text of the semester students were introduced to the academic advisor for their declared major with an infographic which included a picture. Another level of personalization included sending texts specific to students' major to help build community between students, advisors, and faculty in each department. Community building texts were designed to invite students to events or gatherings that promoted interactions with the college community. Examples of an information complexity reducing text and a community building text can be found in the appendix.

Students were eligible for the RFE if they had at least one major in the college and the total credit hours they had earned as of January 2020 were fewer than 100. The total credit hours needed for graduation at the university is 122 , which meant we excluded those students who were most likely to graduate spring semester and thus would be less motivated to engage in new community building activities, but were relatively more motivated to persist and graduate. With those restrictions in place, there were 2225 students eligible to participate in the study. ${ }^{3}$

Students were first screened to assess if the phone number listed on their administrative records was text-eligible through the software program. There were 286 students, or almost $13 \%$ of the eligible participants, whose phone numbers were deemed ineligible because either the listed number was a landline, an international number, or had an error. The remaining students were randomly assigned to one of three groups before the start of the spring 2020 semester:

- Text-Only Treatment (Group 1): In addition to receiving the standard emails from advisors, students in the text-only treatment group were exposed to a text-based communication campaign from their major academic advisor.

- Text+Direct Contact Treatment (Group 2): Students in the text-plus treatment group were exposed to the same text-based communication campaign along with receiving standard email communication from their major advisor. However, these students were also to be registered for a major-specific course enrollment meeting where they were to have the opportunity to interact with their academic advisor, college ambassadors, and university representatives who could answer questions about career paths and scholarships and financial aid.

\footnotetext{
${ }^{3}$ Prior to undertaking the study, a prospective power analysis for logistic regression was done where (1) the impact of the treatment was hypothesized to move the probability of persistence from .80 to .85 , (2) the pseudo R-squared was assumed to be .20 , and (3) the sample size was 2100 . The resulting power was estimated to be 0.77 (Hintz, 2013). While the university publishes the percentage of freshmen who are retained through their sophomore year, information on semester-specific retention rates for all students was not available prior to this study and thus the .80 to .85 estimates were crude approximations.
} 
- Controls (Group 3): Students in the control group were exposed to academic advisors' standard communication plan (e.g., periodically sending out emails regarding upcoming deadlines, posting information on the advising Canvas courses that serve as a resource for declared majors).

The RFE during spring semester 2020 coincided with the beginning of the COVID-19 pandemic. In the middle of March, the university moved all classes to an online delivery mode. In response, we changed some of our messaging in the later part of the semester to re-focus on providing college support during that exceptional time (e.g., asking how classes were going, reminding students that advisors were taking virtual and phone appointments, informing them about emergency food resources). In addition, because the in-person registration event was scheduled for early April, it was moved to a virtual event. We had initially planned to only have group 2 participate in this event, however, with the shift to onlineonly courses, we believed we should expand student supports and made the decision to invite both group 1 and group 2 to the virtual event. Thus, the three groups were collapsed into two.

The treatment group $(\mathrm{N}=1451)$ received an initial text from their major advisor telling them about our plan to use texting as a new communication tool for the spring semester and explaining how they could opt out of the program if they wanted. Only 51 students opted out over the course of the semester with the vast majority of those opting out within the first week or two. ${ }^{4}$ The students who opted out remain in the treatment group for the purposes of the analyses that follow because there was an intent to treat them. The remaining students in the treatment group $(\mathrm{N}=1400)$ were sent approximately one text message per week during the 16-week semester and were invited to a virtual fall course registration event. The students in the control group $(\mathrm{N}=488)$ did not receive text messages from their major advisor and were not invited to the virtual course registration event.

\section{The Outcome Data}

Data on engagement rates and opt-out rates were gathered for the treatment group during spring semester. Data on engagement with the college came from (1) college records on scholarship and student ambassador applications, and (2) the academic advising center's appointment manager program that tracks students' advising appointments. These data were linked to the university's student data warehouse, as it provided information on students' socio-demographics, career stage, and academic outcomes, including spring semester persistence.

Our measures of college engagement were limited to (1) meeting with an academic advisor, (2) applying to be a college student ambassador, and (3) applying for a scholarship for the 2020-2021 academic year. We used two definitions of persistence. First, we measured if a student who began the semester was still enrolled at the university at the end of the semester (i.e., the university's definition of persistence). Second, we measured if a student persisted to the end of the semester at the university and did not change to a major out of the college during the semester (i.e., the college's definition of persistence). Information

\footnotetext{
4 Those who opted out were somewhat different from those who remained in the treatment group in terms of their socio-demographics and their persistence outcomes. See Appendix Table 5 for these comparisons.
} 
Table 1 Summary statistics for analytic demographics and outcome variables

\begin{tabular}{lllll}
\hline Variable & $\begin{array}{l}\text { Full sample } \\
(\mathrm{N}=1939)\end{array}$ & $\begin{array}{l}\text { Control group } \\
(\mathrm{N}=488)\end{array}$ & $\begin{array}{l}\text { Treatment group } \\
(\mathrm{N}=1451)\end{array}$ & $\chi^{2}$ \\
\hline Female & 64.00 & 66.80 & 63.06 & 2.22 \\
Age $>24$ & 15.37 & 17.62 & 14.61 & 2.55 \\
White non-hispanic & 66.53 & 64.14 & 67.33 & 1.67 \\
State resident & 82.26 & 84.43 & 81.53 & 2.10 \\
Upperclass & 57.30 & 61.07 & 56.03 & $3.78^{*}$ \\
Entered as freshman & 69.68 & 67.83 & 70.30 & 1.05 \\
Honors student & 9.18 & 10.45 & 8.75 & 1.26 \\
Cumulative GPA $>3.5$ in Fall 2019 & 25.12 & 26.23 & 24.74 & 0.43 \\
University persistence & 95.51 & 94.47 & 95.86 & 1.66 \\
College persistence & 92.63 & 90.78 & 93.25 & $3.25^{*}$ \\
One or more advising appointment & 51.88 & 51.43 & 52.03 & 0.05 \\
Applied for at least one scholarship & 6.50 & 6.56 & 6.48 & 0.004 \\
Applied to be an ambassador & 2.84 & 4.10 & 2.41 & $3.77^{*}$ \\
\hline
\end{tabular}

$* \mathrm{p}<.10 ; * * \mathrm{p}<.05$

from the student data warehouse was used to ascertain persistence to the end of the semester using these definitions.

Several different partitions of the data were done when analyzing the outcomes. First, we focused on treatment versus control group students regardless of academic career stage. Second, we separated students into those with fewer than 60 credit hours completed and those with 60-99 credit hours completed to see if treatment effects differed by academic career stage. ${ }^{5}$ Finally, we examined how engagement with the texting platform within the treatment group was related to our outcomes of interest. ${ }^{6}$

\section{Bivariate Results}

Table 1 shows the socio-demographic and academic characteristics of the students who were included in the RFE. Randomization was successful with only two marginally significant differences between the control and treatment groups. Students in the treatment group were marginally younger than students in the control group. Students in the treatment group were also less likely to be juniors or seniors than those in the control group. To ensure that the impacts of these differences were controlled for, all analyses were done

\footnotetext{
${ }^{5}$ Frequency of students at each academic career stage are as follows: Freshmen ( $<30$ credit hours) $\mathrm{N}=366$ or $18.88 \%$ of the full sample; sophomore (30-59 credit hours) $\mathrm{N}=462$ or $23.83 \%$ of the full sample; junior (60-89 credit hours) $\mathrm{N}=791$ or $40.79 \%$ of the full sample; and senior (90-99 credit hours) $\mathrm{N}=320$ or $16.50 \%$ of the full sample. The relatively high percentage of students with junior standing can be explained by the fact that approximately $40 \%$ of majors in the college are transfer students, with many students starting at a 2-year college or another in-state 4-year college. The smaller percentage who are seniors is a result of our exclusion of those students near graduation (i.e., those with $100+$ credit hours).

6 Frequency of students in the treatment group who engaged with advisors via text message are as follows: responded to at least one text sent from college $\mathrm{N}=902$ or $62 \%$ and students who did not respond to text messages $\mathrm{N}=549$ or $38 \%$.
} 
Table 2 Summary statistics by student career stage

\begin{tabular}{|c|c|c|c|c|c|c|}
\hline \multirow[t]{2}{*}{ Variable } & \multicolumn{3}{|c|}{ Completed credit hours $<60$} & \multicolumn{3}{|c|}{ Completed credit hours 60-99 } \\
\hline & $\begin{array}{l}\text { Treatment } \\
\text { group } \\
(\mathrm{N}=638)\end{array}$ & $\begin{array}{l}\text { Control } \\
\text { group } \\
(\mathrm{N}=190)\end{array}$ & $\chi^{2}$ & $\begin{array}{l}\text { Treatment } \\
\text { group } \\
(\mathrm{N}=813)\end{array}$ & $\begin{array}{l}\text { Control } \\
\text { group } \\
(\mathrm{N}=298)\end{array}$ & $\chi^{2}$ \\
\hline Female & 65.20 & 71.58 & $2.68^{*}$ & 61.38 & 63.76 & 0.52 \\
\hline Age $>24$ & 11.44 & 13.16 & 0.41 & 17.10 & 20.47 & 1.68 \\
\hline White non-hispanic & 65.67 & 62.63 & 0.60 & 68.63 & 65.10 & 1.25 \\
\hline State resident & 72.88 & 75.79 & 0.64 & 88.31 & 89.93 & 0.57 \\
\hline Upperclass & - & - & - & - & - & - \\
\hline Entered as freshman & 79.15 & 79.47 & 0.01 & 63.35 & 60.40 & 0.81 \\
\hline Honors student & 7.99 & 10.53 & 1.20 & 9.35 & 10.40 & 0.28 \\
\hline $\begin{array}{l}\text { Cumulative GPA > } 3.5 \text { in Fall } \\
2019\end{array}$ & 22.10 & 27.37 & 2.27 & 26.81 & 25.50 & 0.19 \\
\hline University persistence & 94.67 & 90.53 & $4.27 * *$ & 96.80 & 96.98 & 0.88 \\
\hline College persistence & 91.54 & 84.74 & $7.50 * *$ & 94.59 & 94.63 & 0.00 \\
\hline $\begin{array}{l}\text { One or more advising appoint- } \\
\text { ment }\end{array}$ & 49.69 & 42.11 & $3.37^{*}$ & 53.87 & 57.38 & 1.08 \\
\hline $\begin{array}{l}\text { Applied for at least one scholar- } \\
\text { ship }\end{array}$ & 5.49 & 5.79 & 0.03 & 7.26 & 7.05 & 0.01 \\
\hline Applied to be an ambassador & 1.88 & 2.63 & 0.41 & 2.83 & 5.03 & $3.20 *$ \\
\hline
\end{tabular}

$* \mathrm{p}<.10 ; * * \mathrm{p}<.05$

using multivariate logistic regression where the covariates presented in Table 1 were included as control variables.

Table 1 also presents the bivariate differences between the control and treatment groups and the outcome variables of interest. Students in the treatment group were significantly more likely to persist to the end of the semester and stay in a major with the college $(\mathrm{p}<0.05)$, with $90.78 \%$ of students in the control group and $93.86 \%$ of the treatment group persisting to the end of the semester using the college's definition of persistence. Using the university's definition of persistence, $94.47 \%$ of the control group and $96.07 \%$ of the treatment group persisted, but these bivariate differences did not reach conventional levels of statistical significance. As a point of comparison, we requested that institutional analysis provide us with the college's overall persistence rate using the university's definition and found that it has fluctuated between 95.4 and $96.7 \%$ in fall and spring terms in recent years.

Table 2 represents bivariate differences between students with less than 60 credit hours (freshman and sophomore) and students with 60 to 99 credit hours (junior and senior). When looking at university persistence, approximately $94 \%$ of students with less than 60 credit hours persisted to the end of semester in the treatment group while approximately $90 \%$ of students in the control group persisted $(\mathrm{p}<0.05)$. When considering college persistence, $91 \%$ of students in the treatment group and $87 \%$ of students in the control group persisted to the end of the semester $(\mathrm{p}<0.05)$. There were no statistically significant bivariate differences in persistence between treatment and control group students who had completed 60-99 credit hours.

Turning to our measures of engagement, there was evidence of statistically significant differences in engagement with the college by students in the treatment and control groups with (1) student ambassador applications and (2) meeting with an academic advisor. 
Students in the control group were marginally more likely to apply for an ambassador position than were students in the treatment group, and students with $<60$ credit hours were more likely to meet with an academic advisor. However, there was little evidence of difference for the other measures of engagement.

Prior research has also examined whether or not a student in the treatment engaged with the text messaging program (Castleman \& Page, 2014) and therefore we looked for engagement effects as well. The text messaging platform that we used measured student engagement by the number of messages a student sent to their major advisor relative to the number of messages sent from the advisor, whether programmed or manual. This included when a student replied directly to a nudge or reached out to an advisor via text of their own accord. For our analyses, we define engaging with the platform as whether a student sent at least one text message to an advisor over the course of the semester. Approximately $61 \%$ (i.e., 851 students) of treatment group students responded to at least one text message at some point during the semester. Additionally, we found that gender was the only socio-demographic characteristic with statistically significant differences between treatment group students who responded to at least one text message and those who did not. To assess if such engagement matters for our outcomes of interest, we include engagement with the text messaging program as a covariate in one version of the outcome analyses. Descriptive information and the bivariate comparisons of the engagement subgroups is presented in Appendix Table 6.

Tests for multicollinearity among the covariates in our logistic regressions revealed no causes of concern. All data analyses were done in a combination of SAS 9.4 and Stata 16.

\section{Multivariate Results}

Table 3 shows the results of a multivariate logistic regression estimates for university and college persistence outcomes. Results are presented as odds ratios. To facilitate interpretation, predicted probabilities at the modal values for the covariates are also calculated when the odds ratio is statistically significant.

Students who were in the treatment group in the full sample were 1.48 times more likely to persist when using the college's definition of persistence, which equates to a $95 \%$ probability that a student in the treatment group will persist compared to a $93 \%$ probability that a student will persist in the control group. When further divided by academic level, the gap between the treatment and control group predicted probabilities grows for students with fewer than 60 credit hours completed. These treatment group students, those who have fewer than 60 credit hours, were 2.13 times more likely to persist at the university and 2.09 times more likely to persist within the college than otherwise similar students in the control group. These odds ratios equate to $5 \%$ point gain in persistence at the university and a $6 \%$ point gain for persistence in the college, respectively, for those in the freshman/sophomore treatment group. Students who had completed 60 to 99 credit hours showed no significantly different persistence outcomes using either the university or the college measure.

Logistic regression results for advising appointments, scholarship applications, and ambassador applications are presented in Table 4. No statistically significant results were found when comparing the treatment to the control group in the full sample, however, once we differentiate those who engaged with the texting program from those who never responded to a text, things change. The analyses in the bottom portion of Table 4 highlight the importance of student engagement with the text messages as they relate to nudges 


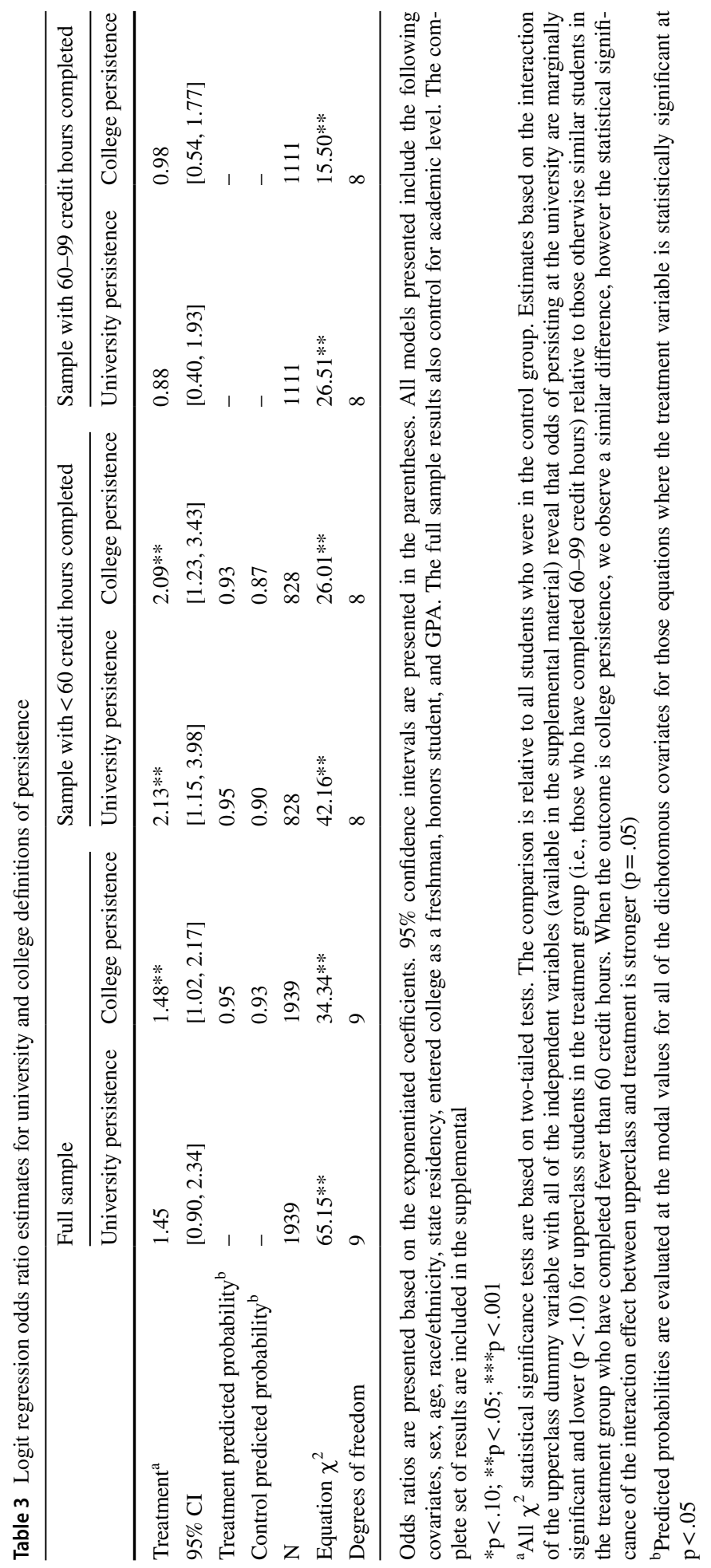




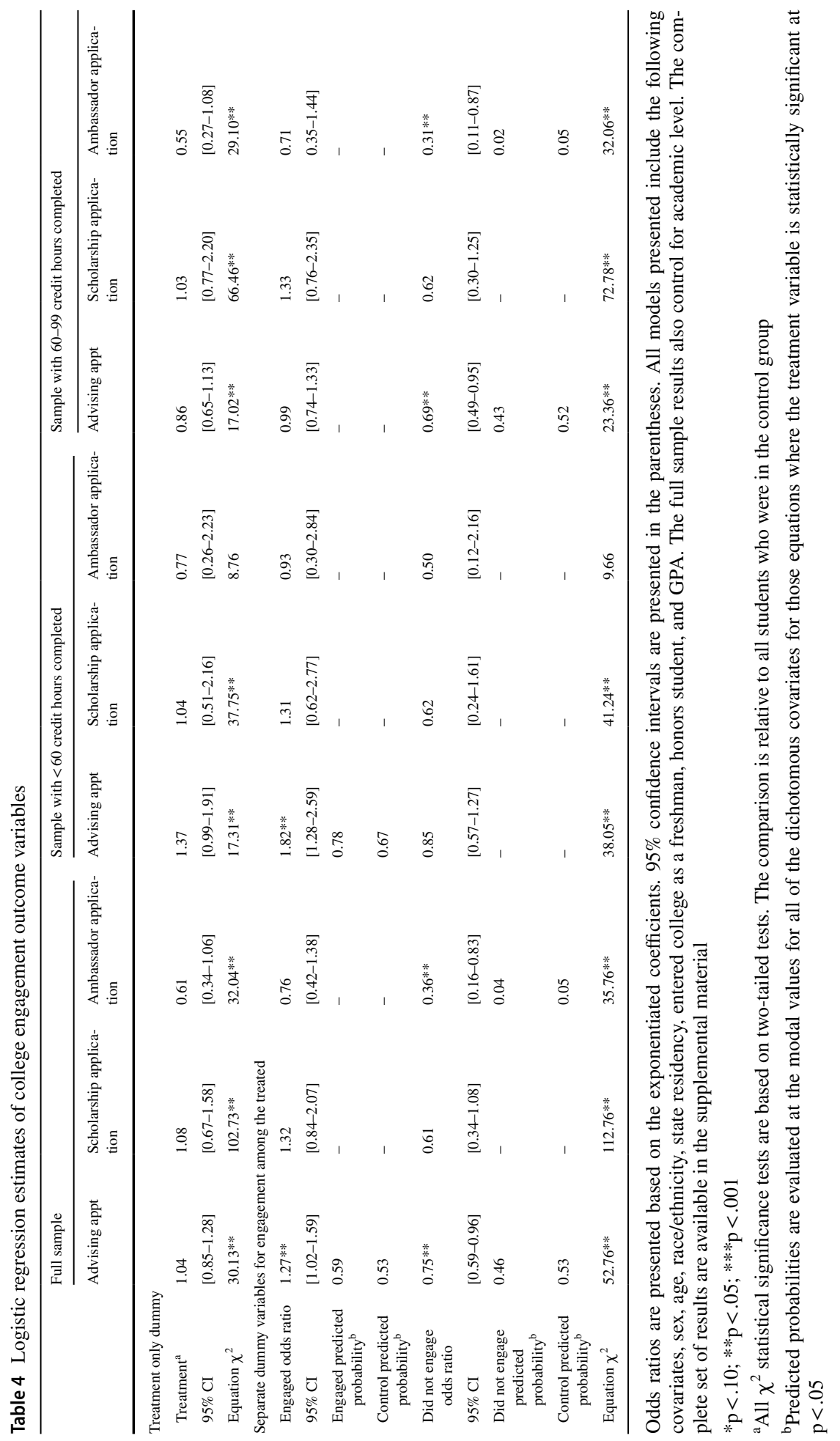


designed to build the student's sense of community and reduce information complexity. Students in the treatment group who responded to one or more message in the full sample were 1.27 times more likely to meet with an advisor than were otherwise similar students in the control group. This is also true for students with less than 60 credit hours, who were 1.82 times more likely to meet with an advisor.

Interestingly, students in the treatment group in the full sample who never responded to a text message had $25 \%$ lower odds of meeting with an advisor compared to students in the control group. In addition, students who did not reply to a message had $64 \%$ lower odds of applying to be an ambassador compared to students in the control group. Students who did not engage and have 60-99 credit hours were 31\% less likely to meet with and advisor and $60 \%$ less likely to submit an application to be an ambassador for the college than otherwise similar students in the control groups.

\section{Discussion and Conclusions}

The results of the RFE suggest the texting intervention significantly increased the likelihood of persistence to the end of the semester in both the college and the university for students who were freshmen or sophomores. Before discussing the implications of these findings, it is important to contextualize the results of our study. First, the study is limited in its generalizability. As a large college within a public university, our student population may differ in important ways from those in other college settings.

Second, the study only followed students for one semester. As such, we were unable to assess the impact of texting on (1) engagement over an extended period of time, or (2) persistence to graduation. However, if impact is shown over a short period of time, it may be reasonable to argue that the impact will change over time. For example, a student who does not engage with an advisor via text in one semester, may utilize the service when more pressing questions or concerns arise as they move through their academic lives, and decision making becomes more complex. ${ }^{7}$ In this context, our results may be conservative. Alternatively, it may be as the texting novelty wears off, students stop reading text messages from advisors. If this is true, then our results may be over-stating the positive impact of the intervention in the long run.

Third, the study has limited measures of engagement. Our data were limited to what could be obtained through academic records and by the level of engagement measured by the texting platform. For example, the platform did not provide the number of messages a student responded to, rather we only had access to categorical measures of low, medium, and high engagement. It would have been helpful to have had additional measures of engagement such as student group or club membership, event attendance, or interactions with faculty as well as a more nuanced measure of enagagement with the texting program.

Finally, students with phone numbers that were not capable of receiving text messages became a surprising case of self-selection. While the majority of students in the college had text-capable phone numbers, 286 students did not, and therefore could not be included in the research design. In reference to the socio-demographics and academic measures we had access to, there was no significant difference between those who had a texting capable

\footnotetext{
${ }^{7}$ From the pilot program in fall 2019 and spring 2020 we have seen an increase in engagement with the text messages, particularly in response to the introduction text at the beginning of each semester. In fall 2019 the engagement rate after the first text was $9.1 \%$, while it was $28.3 \%$ in spring 2020 .
} 
phone and those who did not. However, this does not exclude the chance there are unmeasured differences between the two groups. ${ }^{8}$ The literature on text messaging interventions does not address self-selection of this type, and it should be considered in future studies. ${ }^{9}$

As with many studies conducted since 2020, it is important to consider the impact of the COVID-19 pandemic on outcomes. This study was conducted during the spring semester of 2020. Appromixately half-way through the semester, students, faculty, and staff transistioned to remote learning. The impact of the pandemic on student persistence in unknown. However, it is important to consider that the pandemic could have impacted the study and the overall conclusions of the effect of texting on student persistence.

With the above contextual caveats in mind, we now turn to a discussion of the insights gained from this study. Our study reveals texting can be used to improve persistence outcomes for students early in their academic careers, but did not improve persistence outcomes for students with 60 or more credit hours. These findings are consistent with Tinto's (2015) hypothesis that early intervention is important for student persistence.

Another important component of this study was assessing the impact of text messaging on intermediate levels of enagagement with the college, such as making an advising appointment or applying for a scholarship. Here, our findings reveal the need for further research on what motivates a student to engage or not engage with the texting software. While these groups did not differ in terms of their socio-demographic characteristics other than gender (see Appendix Table 6), they were often strikingly different in terms of their persistence probabilities and intermediate college engagement probabilities. Knowing more about why some students engage with the texting software while others do not could help colleges better target some of their communication efforts.

Confidence in our results is heightened by the fact that the study design required students to opt out, rather than requiring them to opt in, to the intervention. Fishbane and Fletcher (2019), argue the former approach is preferred if one is to reach a representative sample, as students who do not see an immediate benefit may be different in their approach to college than those who do. Indeed, behavioral economics suggests students often make decisions that provide immediate gratification over those that will positively impact their futures (Hanushek et al., 2016). Requiring students to opt-out rather than opt-in reduced the opportunity for such self-selection. Studies on text messaging have found mixed results when students have been asked to opt-in to texting interventions (Castleman \& Meyer, 2020; Dobronyi et al., 2017; Oreopoulos \& Petronijevic, 2018).

\footnotetext{
${ }^{8}$ In one set of analyses, the Heckman correction for self-selection was used to account for possible difference between those in the study who had a text-capable phone number and those who did not. Across all outcomes, correction for such sample selection (i.e., the coefficient associated with lambda) was statistically insignificant. We also reached back to the spring 2019 semester to get data on the subset of students who were majors in the college and registered both terms to undertake a difference-in-difference analysis that adjusts for unmeasured, unchanging predispositions. Again, the results were not statistically significant, perhaps in part, because of the reduction in sample size. All of these alternate estimation results are available from the authors upon request.

9 Some of the students who were deemed ineligible for the study had international phone numbers. International students could benefit from programs that utilize text messaging nudges to bridge potential language and cultural differences that are expected when attending a foreign college or university. However, the text messaging platform we used did not allow texting to international phone numbers due to regulatory and delivery issues associate with interational carriers. A college or university interested in texting international students may want to work with their chosen text messaging company on this issue, though they would want to ensure that any program they selected was FERPA compliant.
} 
Our research design utilized best practices in constructing regular, proactive, and personalized messages. The program provided weekly messages that connected students with academic advisors and used infographics to further reduce informational complexity. The infographics provided step by step action items students could take to apply for scholarships, to be an ambassador, fill out required financial aid forms, and make an appointment with an academic advisor. The additional infographics attempted to reduce barriers that may prevent a student from taking action that is advantageous to their academic futures.

In addition to sending text messages and infographics that benefitted the entire student population of the college, our intervention connected students with academic advisors who had expertise in their declared major. Students received selected messages that were specific to their major, including messages inviting them to major-specific events and special course offerings that may have been of interest. Connecting students with these advisors may have increased their likelihood of persistence within the major as these advisors were positioned to understand the students' unique challenges and advise on options that might affect their academic goals. Building a relationship between students and their major advisor early has clear benefits to helping students navigate their major requirements to ensure they make it to the following semester.

It is important to note our research utilized two definitions of persistence, one from the perspective of the university and one from that of the student's major college. Of particular interest may be the findings that utilize the college-specific definition. Recent research shows students who change majors multiple times in their academic careers are more likely to take longer to graduate (Abdou, 2019; Bullock, 2017). Our results suggest an added benefit of texting may be that it reduces a student's likelihood of switching majors which in turn may promote more timely graduation.

Finally, this study's findings provide direction for future research on the effectiveness of text messaging as a mode of communication between academic advisors and college students. Specifically, it is important to know more about what the longer-term impacts of text messaging communications might be. Does it promote greater student engagement over time or do students increasingly ignore or delete these messages without reading them? In addition, more research is needed to understand how different segments of the student population respond to text messaging from advisors. One segment of the population we need to know more about are students who do not have text-capable phones or who decline to share their text-capable phone numbers with the institution. Is this group being adequately served by other modes of communication from the institution? Another segment of interest consists of those students who have text-capable phones but who never engage with an advisor through texting. Our initial research suggests that this latter group may be at a somewhat greater risk of engaging in behaviors that do not promote persistence in the long run. If that is true, then knowing more about who these students are could help advisors better craft targeted messages or utilize different communication strategies to reach them.

\section{Appendix 1}

Examples of texts sent to students in spring 2020:

Reducing information complexity:

Did you know that the Political Science Department hosts multiple campus and community events throughout the semester? Get connected and don't miss a single Political Science event! Follow us on Facebook, Instagram, and Twitter @UofUPoliScience.

Community bulding: 
Table 5 Descriptive information on treatment group students by opt-out status

\begin{tabular}{lllc}
\hline Variable & $\begin{array}{l}\text { Maintained enrollment in } \\
\text { texting program }(\mathrm{N}=1400)\end{array}$ & $\begin{array}{l}\text { Opted out of the texting } \\
\text { program }(\mathrm{N}=51)\end{array}$ & $\chi^{2}$ Test \\
\hline Female & 0.63 & 0.64 & 0.06 \\
Age $>24$ & 0.14 & 0.20 & 1.06 \\
White non-hispanic & 0.68 & 0.59 & 1.74 \\
State resident & 0.81 & 0.92 & $3.96^{* *}$ \\
Upperclass & 0.56 & 0.51 & 0.55 \\
Entered as freshman & 0.71 & 0.61 & 2.29 \\
Honors student & 0.09 & 0.04 & 1.54 \\
Cumulative GPA $>3.5$ in Fall 2019 & 0.25 & 0.20 & 0.75 \\
University persistence & 0.96 & 0.90 & $4.29 * *$ \\
College persistence & 0.94 & 0.76 & $23.62^{* *}$ \\
One or more advising appointment & 0.52 & 0.49 & 0.19 \\
Applied for at least one scholarship & 0.07 & 0.02 & 1.78 \\
Applied to be an ambassador & 0.03 & 0.0 & 1.31 \\
\hline
\end{tabular}

$* * \mathrm{p}<.05$

Table 6 Summary statistics for treatment group by student engagement

\begin{tabular}{llcc}
\hline Variable & $\begin{array}{l}\text { Responded to zero text } \\
\text { messages (N=549) }\end{array}$ & $\begin{array}{l}\text { Responded to } \geq 1 \text { text } \\
\text { message (N=902) }\end{array}$ & $\chi^{2}$ \\
\hline Female & 59.74 & 65.08 & $4.17^{* *}$ \\
Age $>24$ & 13.11 & 15.52 & 1.58 \\
White non-hispanic & 68.67 & 66.52 & 0.72 \\
State resident & 81.24 & 81.71 & 0.05 \\
Upperclass & 55.65 & 55.65 & 0.14 \\
Entered as freshman & 71.04 & 69.84 & 0.23 \\
Honors student & 10.02 & 7.98 & 1.77 \\
Cumulative GPA $>3.5$ in Fall 2019 & 25.14 & 24.50 & 0.07 \\
University persistence & 95.99 & 95.79 & 0.04 \\
College persistence & 93.62 & 93.02 & 0.20 \\
One or more advising appointment & 44.08 & 56.87 & $22.38^{* *}$ \\
Applied for at least one scholarship & 4.19 & 7.87 & $7.64^{* *}$ \\
Applied to be an ambassador & 1.46 & 2.99 & $3.42^{*}$ \\
\hline
\end{tabular}

$* \mathrm{p}<.10 ; * * \mathrm{p}<.05$ 
Hi [preferred_name], it's [advisor]. I'm here to answer questions you have during this time of many changes at the U. I also want to remind you that registration for Summer opened March 23rd and Fall opens April 13th. For helpful information on "How to Navigate Registering for Summer or Fall 2020" and to schedule phone or virtual appointment with me or an advisor on our team use this link: https://csbs.utah.edu/people/ds-advising/index.php

See Tables 5 and 6.

Supplementary Information The online version contains supplementary material available at https://doi. org/10.1007/s11162-022-09678-8.

Funding The research contained in this paper was supported by the Degree Completion Challenge at the University of Utah.

\section{References}

Abdou, N. W. (2019) Predictors of four-year graduation rates: A quantitative study on the impact of enrollment in major related course, student engagement, and student-faculty interactions on graduation rates of first-time student. Dissertation, California State Univerity, Fullteron.

Aljohani, O. (2016). A comprehensive review of the major studies and theoretical models of student retention in higher education. Higher Education Studies, 6(2), 1-18.

Allen, J., Robbins, S. B., Casillas, A., \& Oh, I.-S. (2008). Third-year college retention and transfer: Effects of academic performance, motivation, and social connectedness. Research in Higher Education, 49(7), 647-664. https://doi.org/10.1007/s11162-008-9098-3

Arnold, K. D., Israni, V., \& Rohn, K. C. (2020). The student experience of two-way text-message college advising: A first glimpse. Journal of College Access, 5(2), 6.

Astin, A. W. (1975). Preventing students from dropping out. Jossey-Bass.

Bai, H., \& Pan, W. (2009). A multilevel approach to assessing the interaction effects on college student retention. Journal of College Student Retention: Research, Theory \& Practice, 11(2), 287-301. https:// doi.org/10.2190/CS.11.2.g

Bettinger, E. P., \& Baker, R. B. (2014). The effects of student coaching: An evaluation of a randomized experiment in student advising. Educational Evaluation and Policy Analysis, 36(1), 3-19.

Boath, E., Jinks, A., Thomas, N., Thompson, R., Evans, J., O'Connell, P., et al. (2016). Don't do with the 'FLO'-A student mobile texting service to enhance nursing student retention. Nurse Education Today, 45, 80-86.

Boyd, N. M., Liu, X., \& Horissian, K. (2020). Impact of community experiences on student retention perceptions and satisfaction in higher education. Journal of College Student Retention: Research, Theory \& Practice. https://doi.org/10.1177/1521025120916433

Bullock, C. D. (2017) Factors that influence graduation efficiency of baccalaureate recipients at Weber State University. Doctoral dissertation. University of Utah.

Casey, B., Jones, R. M., \& Somerville, L. H. (2011). Braking and accelerating of the adolescent brain. Journal of Research on Adolescence, 21(1), 21-33.

Castleman, B. L. (2015). The 160-character solution: How text messaging and other behavioral strategies can improve education. Johns Hopkins University Press.

Castleman, B. L., \& Meyer, K. E. (2020). Can text message nudges improve academic outcomes in college? Evidence from a West Virginia intiative. The Review of Higher Education, 43(4), 1125-1165.

Castleman, B. L., \& Page, L. C. (2014). Summer nudging: Can personalized text messages and peer mentor outreach increase college going among low-income high school graduates? Journal of Economic Behavior \& Organization, 115, 114-160. https://doi.org/10.1016/j.jebo.2014.12.008

Castleman, B. L., \& Page, L. C. (2015). Summer nudging: Can personalized text messages and peer mentor outreach increase college going among low-income high school graduates? Journal of Economic Behavior \& Organization, 115, 114-160. https://doi.org/10.1016/j.jebo.2014.12.008

Castleman, B. L., \& Page, L. C. (2016a). Can text messages mitigate summer melt? New England Journal of Higher Education. 
Castleman, B. L., \& Page, L. C. (2016b). Freshman year financial aid nudges: An experiment to increase FAFSA renewal and college persistence. Journal of Human Resources, 51(2), 389-415.

Castleman, B. L., \& Page, L. C. (2017). Parental influences on postsecondary decision making: Evidence from a text messaging experiment. Educational Evaluation and Policy Analysis, 39(2), 361-377.

Corbett, C., Hill, C., \& Rose, A. S. (2008). Where the girls are: The facts about gender equality in education. American Association of University Women Education Foundation.

Davidson, W. B., Beck, H. P., \& Milligan, M. (2009). The college persistence questionnaire: Development and validation of an instrument that predicts student attrition. Journal of College Student Retention: Research, Theory \& Practice, 50(4), 373-390. https://doi.org/10.1353/csd.0.0079

Deil-Amen, R., \& Rosenbaum, J. E. (2003). The social prerequisites of success: Can college structure reduce the need for social know-how? Annals of the American Academy of Political and Social Science, 586(1), 120-143. https://doi.org/10.1177/0002716202250216

Dobronyi, C. R., Oreopoulos, P., \& Petronijevic, U. (2017). Goal setting, academic reminders, and college success: A large-scale field experiment. NBER Working Paper. National Bureau of Economic Research.

Fishbane, A., \& Fletcher, E. (2016). Nudging for Success: Using behavioral science to improve the postsecondary student journey. Ideas 42.

Fishbane, A., \& Fletcher, E. (2019). Nudges, norms, and new solutions: Evidence-based strategies to get students to \& through college. Ideas 42 .

Goldrick-Rab, S. (2010). Challenges and opportunities for improving college student success. Review of Educational Research, 80(3), 437-469. https://doi.org/10.3102/0034654310370163

Hagedorn, L. S., Maxwell, W., \& Hampton, P. (2001). Correlates of retention for African-American males in community colleges. Journal of College Student Retention: Research, Theory \& Practice, 3(3), 243-263. https://doi.org/10.2190/MJ6A-TFAC-MRPG-XDKL

Hanushek, E. A., Machin, S. J., \& Woessmann, L. (Eds.). (2016). Handbook of the economics of education. Elsevier.

Hawley, T. H., \& Harris, T. A. (2005). Student characteristics related to persistence for first-year community college students. Journal of College Student Retention: Research, Theory \& Practice, 7(1-2), 117142. https://doi.org/10.2190/E99D-V4NT-71VF-83DC

Hintz, J. (2013). PASS 12. NCSS, LLC. Retrieved at www.ncss.com

Jorgenson, D. A., Farrell, L. C., Fudge, J. L., \& Pritchard, A. (2018). College connectedness: The student perspective. Journal of the Scholarship of Teaching and Learning, 18(1), 75-95. https://doi.org/10. 14434/josotl.v18i1.22371

Kahn, P. E. (2014). Theorising student engagement in higher education. British Educational Research Journal, 40(6), 1005-1018. https://doi.org/10.1002/berj.3121

Kot, F. C. (2014). The impact of centralized advising on first-year academic performance and secondyear enrollment behavior. Research in Higher Education, 55(6), 527-563. https://doi.org/10.1007/ s11162-013-9325-4

Krijnen, J. M., Tannenbaum, D., \& Fox, C. R. (2017). Choice architecture 2.0: Behavioral policy as an implicit social interaction. Behavioral Science \& Policy, 3(2), 1-18.

Kuh, G. D., Cruce, T. M., Shoup, R., Kinzie, J., \& Gonyea, R. M. (2008). Unmasking the effects of student engagement on first-year college grades and persistence. The Journal of Higher Education, 79(5), 540-563.

Langlois, C., \& Klein, G. 2020. (2019) Why students don't read emails. Peoplocity. Indianapolis, IN: Peoplocity September 21. Retrieved from https://peoplocity.com/2019/02/05/read-emails/

Ly, K., Mažar, N., Zhao, M., \& Soman, D. (2013). A practitioner's guide to nudging. Rotman School of Management Working Paper, (2609347).

Mabel, Z., Castleman, B. L., \& Bettinger, E. P. (2019). Finishing the last lap: Experimental evidence on strategies to increase college completetion for students at rish of late departure. Working Paper.

Marsh, G. (2014). Institutional characteristics and student retention in 4-year colleges and universities. Journal of College Student Retention: Research, Theory \& Practice, 16(1), 127-151. https://doi.org/10. 2190/CS.16.1.g

National Center for Education Statistics. (2019). College navigator. U.S. Department of Education. Retrieved May 5, 2020 from https://nces.ed.gov/collegenavigator/?q=University+of+Utah\&s=all

National Center for Education Statistics. (2020). Digest of eduation statistics. National Center for Educartion Statistics. Retrieved July 19, 2021 from https://nces.ed.gov/programs/digest/d20/tables/dt20_326. 10.asp

Oreopoulos, P., Patterson, R. W., Petronijevic, U., \& Pope, N. G. (2019). Low-touch attempts to improve time management among traditional and online college students. Journal of Human Resources, 57, 1-43. 
Oreopoulos, P., \& Petronijevic, U. (2018). Student coaching: How far can technology go? The Journal of Human Resources. https://doi.org/10.3368/jhr.53.2.1216-8439R

Page, L. C., \& Gehlbach, H. (2017). How an artificially intelligent virtual assistant helps students navigate the road to college. AERA Open. https://doi.org/10.1177/2332858417749220

Page, L. C., Lee, J., and Gehlbach, H.. (2020). Conditions under which college students can be responsive to nudging. (EdWorkingPaper: 20-242). Retrieved from Annenberg Institute at Brown University: https:// doi.org/10.26300/vjfs-kv29

Panek, E. (2014). Left to their own devices: College students' "guilty pleasure" media use and time management. Communication Research, 41(4), 561-577. https://doi.org/10.1177/0093650213499657

Schwebel, D. C., Walburn, N. C., Jacobsen, S. H., Jerrolds, K. L., \& Klyce, K. (2008). Efficacy of intrusively advising first-year students via frequent reminders for advising appointments. NACADA Journal, $28(2), 28-32$.

Selingo, J. J. (2018). The new generation of students: How colleges can recruit, teach, and serve Gen Z. The Chronicle of Higher Education.

Snyder, T. D., Brey, C. D., \& Dillow, S. A. (2019). Digest of education statistics 2018 (NCES 2020009). National Center for Education Statistics, Institute of Education Services, U.S. Department of Education.

Stewart, S., Lim, D. H., \& Kim, J. (2015). Factors influencing college persistence for first-time students. Journal of Developmental Education, 38(12-16), 18-20.

Stiles, R. J., \& Wilcox, K. (2016). Blending human intelligence and analytics for student success. Journal of Educause Learning Initiative.

Stone, A. (2004). Mobile scaffolding: An experiment in using SMS text messaging to support first year university students. (Paper presented at the IEEE international conference on advanced learning technologies)

Straumsheim, C. (2016). Read and unread. Retrieved September 21, 2020 from https://www.insidehighered. com/news/2016/03/02/study-explores-impact-social-media-texting-email-use

The Office of Budget and Institutional Analysis. (2020). The University of Utah. https://www.obia.utah.edu/ data/

Thaler, R. H., \& Sunstein, C. R. (2009). Nudge: Improving decisions about health, wealth, and happiness. Penguin Books.

Tinto, V. (2015). Through the eyes of students. Journal of College Student Retention: Research, Theory \& Practice, 19(3), 254-269.

Tinto, V. (2017). Reflections on student persistence. Student Success, 8(2), 1-8. https://doi.org/10.5204/ssj. $\mathrm{v} 8 \mathrm{i} 2.376$

Tippetts, M. M., Brandley, A. T., Metro, J., King, M., Ogren, C., \& Zick, C. D. (2020). Promoting persistence: The role of academic advisors. Journal of College Student Retention: Research, Theory \& Practice. https://doi.org/10.1177/1521025120924804

Tippetts, M., Davis, B., \& Zick, C. D. (2021). Texting as an advising communication tool: A case study of receptivity and resistance. Journal of College Student Retention: Research, Theory \& Practice. https:// doi.org/10.1177/15210251211033549

Tough, P. (2019). The years that matter most: How college makes or breaks us. Houghton Mifflin Harcourt.

Tuttle, K. N. (2000). Academic advising. New Directions for Higher Education, 111, 15-24.

Venit, E. 2020. (2017). 'The evolution of academic advising-And what comes next' Insights. Washington DC: EAB May 28. Retrieved from https://eab.com/insights/blogs/student-success/the-evolution-ofacademic-advising-and-what-comes-next/.

Wang, X. (2009). Baccalaureate attainment and college persistence of community college transfer students. Research in Higher Education, 50(6), 570-588. https://doi.org/10.1007/s11162-009-9133-z

Witten, D., James, A., \& Roberts, C. (2017). Factors that contribute to a sense of belonging in business students on a small 4-year. Journal of College Student Retention: Research, Theory \& Practice, 22(1), 99-117. https://doi.org/10.1177/1521025117726520

Yeager, D. S., Hanselman, P., Walton, G. M., Murray, J. S., Crosnoe, R., Muller, C., Tipton, E., Schneider, B., Hulleman, C. S., Hinojosa, C. P., Paunesku, D., Romero, C., Flint, K., Roberts, A., Trott, J., Iachan, R., Buontempo, J., Yang, S. M., Carvalho, C. M., ... Dweck, C. S. (2019). A national experiment reveals where a growth mindset improves achievement. Nature, 573(7774), 364-369. https://doi.org/ 10.1038/s41586-019-1466-y

Publisher's Note Springer Nature remains neutral with regard to jurisdictional claims in published maps and institutional affiliations. 